\title{
CRITICAL ANALYSIS ON THE EXISTING PSYCHO-SPIRITUAL SUPPORT MODELS FOR DISASTER VICTIMS
}

\author{
Rafeah Saidon \\ Senior lecturer, Academy of Contemporary Islamic Studies (ACIS), Universiti Teknologi MARA Shah \\ Alam, 40450 Shah Alam, Selangor Malaysia, e mail: rafeahsaidon@hotmail.com \\ Siti Khadijah Ab. Manan \\ Assoc. Prof. Academy of Contemporary Islamic Studies (ACIS), Universiti Teknologi MARA Shah \\ Alam, 4045, Shah Alam, Selangor Malaysia, email: sitik274@,salam.uitm.edu.my \\ Noorul Huda Sahari \\ Senior lecturer, Academy of Contemporary Islamic Studies (ACIS), Universiti Teknologi MARA Shah \\ Alam, 40450 Shah Alam, Selangor Malaysia, \\ e mail: nooru088@gmail.com \\ Asmak Husin \\ Lecturer, Academy of Contemporary Islamic Studies (ACIS), Universiti Teknologi MARA Shah Alam, \\ 40450 Shah Alam, Selangor Malaysia, \\ e mail: asmak husin@salam.uitm.edu.my
}

Fairuz Nazri

Assoc. Prof. Psychiatry Department, Universiti Kebangsaan Malaysia (UKM), 43600, Bangi Selangor, Malaysia, email: fairuzn@ppukm.ukm.edu.my

Rosilawati Sueb

Senior lecturer, Faculty of Education, Universiti Teknologi MARA Shah Alam, 40450 Shah Alam, Selangor Malaysia, email: rosila334@uitm.edu.my

Nurul Sakinah Aziz

Master's candidate, Academy of Contemporary Islamic Studies (ACIS), Universiti Teknologi MARA Shah Alam, 40450 Shah Alam, Selangor Malaysia,email : nurulsakinah.uitm@gmail.com

\begin{abstract}
Disasters such as flood, earthquake, war and conflict will cause psychological distress to the victims. Psycho-spiritual support plays an important role in coping with stressful experiences. Unfortunately, in any disasters or calamities, psycho-spiritual consequences are given less emphasis compared to material losses. To date, the extent of psychological and psychiatric morbidity that may have been a consequence has been studied only to a limited extent. Research on the effectiveness of psychospiritual supports to prevent or address such problem is even more limited. Therefore, this research is carried out to critically analyse the existing psycho-spiritual support model for disaster victims. The study adopts an exploratory qualitative approach using library research. Findings of this research show that there are variety models of psycho-spiritual support system used in dealing with disaster victims. However, there are some loopholes found, the most important is the absence of comprehensive religious- based model that can be referred. The study suggests that since religion could serve as a psychological and social resource for coping with psychological problems of the disaster victims, it should be taken into consideration in treating the victims.
\end{abstract}

Keywords: psyhco spiritual, disaster victims 


\section{Introduction}

Disasters or calamities consists of two types, i.e natural disasters such as earthquake, volcanic eruptions etc, and man-made disaster such as war and conflicts. In the last decade, countries with the highest number of death due to disaster were Somalia, Ethiopia and Haiti in Africa, Myanmar and China in Asia, the Russian Federation and the Czech Republic in Europe, Australia and Papua New Guinea in Oceania (IFRC, 2016).

Disasters have significant adverse effects not only in the form of material loss, but more importantly is the mental health of the affected populations, including children, women and other vulnerable groups. The loss of their loved ones, their shelters and communities will make the recovery process longer and more difficult (Suhaimi, A. W. \& Marzuki, N. A. 2016).

Studies have shown the variety of psychological impacts due to natural or man-made disasters. This includes depression, anxiety and mental disturbance. Mental disturbances may appear in one's inability to focus, depression, anxiety, intrusive thoughts and nightmares (Pamela V. V., \& Thomas, E. S., 2002). These psychological traumas were due to the victims' exposure to injury and death of others, disruption of the physical environment, or as a consequence of the terror and helplessness that these incidences evoke (Santiago P.N., Oravec G.J., Ursano R.J. (2018).

In Malaysia, study on the psychological effect on victims of Johor flood 2006/2007showed that the victims suffered cognitive, emotional and behavioural shortfalls such as fear, anxiety, hopelessness, helplessness and depression (R. Nasir, A.Z. Zainah \& R. Khairudin, 2012).

Interestingly, studies indicated that higher level of religious involvement is associated with greater wellbeing and mental health (Alexander, M. A., Lotufo, N., \& Koenig, 2008). In fact, many victims of stressful situations seek support from religious figures, professionals, or from friends, while others emphasize silence, isolation, collapse and/or victimization (Bonanno, 2004; Spouse, 1999). Victims with strong religious belief could cope better with traumatic events and could have reconciled easily to meet their everyday life. A nationwide survey of stress reactions in the US after September 11 found that turning to religion such as prayer, religion or spiritual feelings was the second most common way of coping (90\%), after talking with others (98\%) (Schuster et al., 2001).

Victims who instinctively seek spiritual support in crisis have a hopeful expectancy that prayer, spiritual guidance and sacraments will be helpful in alleviating their pain or sense of loss. Pargamat (1997) believes that religion is able to provide suitable resources for individuals to cope with threatening situation. Thus, this research aims to analyse the existing psycho-spiritual support models and to highlight the religious involvement in treating the disaster victims.

\section{Literature Review}

Psycho-spiritual well-being is a subjective experience that incorporates both emotional health and meaning-in-life. It includes self-awareness, coping and adjusting effectively with stress, having satisfying relationships and connectedness with others, sense of faith, sense of empowerment and confidence, and living with meaning and hope (Hung \& Susan, 2003). Preserving the psycho-spiritual well-being of any disaster victims is important as the absence may lead to a distrust of God (Michael, 2008).

World Health Organization (WHO) has been in the forefront of response to emergencies and mental health care is an important part of this response. WHO's policy on mental health and psychosocial support to disaster victims is that it should be community-based and culturally appropriate and take into account the needs of special groups such as children, women, the elderly, etc. WHO recommends for psychosocial support to be provided to affected communities by community-based workers or volunteers who understand the needs of victims and are trained by experts in psychosocial support methodologies. The question is how can we build agreement among key international stakeholders on a better, joint system for the mental health response to disasters (Conference, Aspects, \& Disaster, 2018)

The role of the WHO lies in defining the psychosocial and mental health needs of the community, establishing technical guidelines to be used, providing technical support to governments, NGOs and other stakeholders involved in psychosocial support, as well as training people for implementation of psychosocial support strategies, monitoring and evaluation of programmes and working with governments to develop mental health services.

The report by International Federation of Red Cross and Red Crescent Societies explores the importance of mental health and psychosocial support for those affected by crises and makes the case that more effort is needed in this often-underestimated area. It reviews the nature of partnership between key actors and argues that more attention is needed in building more equitable relationships 
based on trust and transparency. Finally, the report considers the future role of a resilience approach in the face of threats including climate change, conflict and violence (IFRC, 2016)

The other relevant writings on this topic are the articles written by Kucera, (2017); O'Connel, (2017); Qamrul, (2011) and Sarah, et al, (2012). O' Connel (2017) and Qamrul, (2011) highlighted several important issues such as facing psychological sickness, controlling the temptation, averting a disaster and reaction to distressing news. Interestingly, they suggested the way to manage the distress in life by summarizing eleven activities or ways which would enhance individual strength and eradicate distress. Sarah, et al. (2012), on the other hand recommended Islam as an alternative healing practice for treating depression. Similarly, Kucera (2017) stressed that religion may serve as a psychological and social resource for coping with stress. In the case of dealing with loss, Nooria (2003) advised Muslims to comfort the bereaved person by visiting them, strengthening their faith, offering them food, and reciting the Qur'an.

Sipon et al., (2014) in their study observed that flood victims experienced moderate to severe levels of depression, anxiety and stress. The psychological condition of the flood victims must be given careful attention as it may affect not only their psychological wellbeing but also religious belief. However, an extreme negative religious coping may lead to the wrong aqidah or Islamic belief. Despite the severe and some extreme level of anxiety, the majority of the respondents does have high positive religious coping of striving for life transformation, which indicate that the respondents are still optimistic and having positive hope for future and also towards God. Their findings implied the need to inculcate religious values while providing emotional and social support to flood victims to cope with stress. They recommended for future study to be conducted in exploring the coping strategies among flood victims using exploratory mixed method.

Pransky \& Kelley (2014) viewed the important principles of universal mind, consciousness, and thought, in which they explain that mental health is innate and effortless and is produced by a natural, God-given thought process inherent in higher levels of conscious- ness accessed via a free and clear mind. The logic of these three spiritual principles proposes that with a shift in consciousness to higher levels via new insight, people can realize their inner mental health, recognize how to access it so it becomes a lifestyle, and see how to prevent their unhealthy thinking from infecting the present.

This understanding suggests that psychological dysfunction can be avoided by people, regardless of their circumstances, through understanding, realizing, and recognizing in the moment how they are using the power of thought. Nevertheless more rigorous, controlled research is needed to test the logic of this understanding and the effectiveness of the intervention grounded in these principles (Pransky \& Kelley, 2014).

As for the counsellors, a true picture of the mental and psychological state of the victims would be able to give an idea of the kind of intervention techniques or approaches to use. What can be learned from the Johor flood is that those involved in flood should have been more prepared both physically and psychologically. They should have strong social support from people who are equipped with knowledge and skills on how to manage and prevent from stress, anxiety, post-traumatic stress disorder (PTSD) and other problems relating to the effects of natural disaster (R. Nasir, A.Z. Zainah \& R. Khairudin, 2012)

When a disaster strikes, psychological preparedness is one of the most essential factors needed to oversee and adapt individual reactions before and during a disaster, with the objective to enhance the individual conduct and psychological reaction. Present study reveals that psychological preparedness is not the same as physical readiness since it is identified as an intra- individual and mental condition of mindfulness, expectation, and availability (Waqi Suhaimi, Ahmad Marzuki, 2016).

Spiritual and inwardly reflective practices can be adopted in support of non-violent action, either alone or in groups. Prayer and meditation type of activities can provide reassurance and express solidarity (Moore, 2014).

Che Haslina et al (2012), made a comparative study between the Western and Islam relating to the method of treatment of Generalized Anxiety Disorder (GAD). Interestingly they claimed that although Islam does not provide a specific treatment to cure GAD, there are methods that had been used by the previous Islamic scholars and theologians to heal such mental illness through the practice of Al-Quran and Hadith and the implementation of the Muslim scholars' practice in the past. These had been proven successful by all the scholars during the golden Islamic civilization. Among the methods that had been practiced were being faithful to God, performing prayer, practicing specific chant and prayer, being happy and also being patient with God's certainty. Obviously, religious mechanisms with the spiritual approaches gave positive effects compared to the western treatments which can only cure patients physically. 
With regard to counselling as a good solution in treating depression, study by Shadiya (2011) and Aisha (2008) proposed an Islamic counselling skills and techniques by using the Quran and the Sunnah. Amazingly, Aisha (2008) has successfully demonstrates the effectiveness of the integration of spirituality into psychotherapy. She discussed various beliefs in the Islamic faith that may be incorporated into the counselling process by focusing on a cognitive restructuring model. Interestingly, in addressing depression in Muslim Communities, Shaista (2012) found that clients were interested for religious belief to be incorporated into therapy.

IqraSense (2013), in her book provides an Islamic guidance on the spiritual treatment using the Quran and the Sunnah of the Prophet. She provides Islamic guidelines on dealing with life's challenges and hardship.

For the Asian continent, it is quite unfortunate to say that, even though there were a number of disasters happened, limited data were available relating to the psychosocial responses to disaster. This was highlighted by Suresh et al. (2008). They generally outlined the psychosocial intervention efforts from nine Asian nations when confronted with large-scale natural catastrophic events.

In conclusion, it is to be noted that the reviewed literatures are useful in understanding the general features of psycho-spiritual support systems for disaster victims. However, there are some other criteria that should be taken into consideration.

\section{Methodology of Research}

This research aims to critically analyse the existing psycho-spiritual support model for disaster victims. To achieve such objective, the appropriate method adopted in this research is an exploratory qualitative approach using library research. Relevant literatures from the existing texts and previous studies were reviewed to analyse the weaknesses of the existing psycho spiritual support for disaster victims. Writings in journals, books, reports and other reliable sources were scrutinised to find out some loopholes and weaknesses in the existing system. The scope of this study revolved around the existing psycho-spiritual support models for disaster victims adopted by both local and international organizations.

\section{Findings and Discussion}

Below are the existing models of psycho spiritual support for disaster victims.

\section{i. Disaster Continuity of Care Model (DCC)}

DCC model by Pamela V. V., \& Thomas (2002), suggests 4 stages of disaster response to provide continuity of care as follows:

a) preparation

Under this stage, there are two critical incident stress management i.e, educate public prior disaster about emotional reactions to disaster and prepare for debriefing after disaster.

b) warning

Warning stage serves two purposes, first, it issues specific, clearly stated warnings and second, it facilitates the public's ability to take in the message and believe the warning that just been issued.

c) impact

It is the stage at which emergency service workers are called and all systems work together in search and rescue efforts

d) aftermath-

It involves re-establishing equilibrium after a time of tremendous disruption. Long lasting efforts at repairing disrupted economic, physical psychological, social and spiritual systems take place during the aftermath stage. (Pamela V. V., \& Thomas, 2002).

\section{ii. WHO psychological first aid}

WHO (2011) provides psychological first aid action principles which are summarised as follows:

i.PREPARE; This is the beginning stage that requires the workers to learn about the available services or supports and also learn about safety and security concerns.

ii. LOOK- this involves checking the safety of the victims, checking victims' obvious urgent basic needs and also those who have serious distress reactions.

iii. LISTEN- this can be done by approaching victims and ask their needs and concerns. The more important is listen and help them to feel calm. 
iv. LINK - this means helping victims address their basic needs, cope with problems and connect

them with family and social support.

In addition to those principles, WHO also offers ethical do's and don'ts as guidance to provide the best care possible to the victims.

\section{iii: Holistic Flow Model of Spiritual Wellness}

This model enhances holistic wellness by purposely developing components of an individual's spirit. It describes the component of spirit and how they affect life tasks.

In this model, spirituality is the central force that determines an individual's health and satisfaction with each dimension. There are several elements emphasised in this model (Melanie,P. \& Peggy D., 2005) i.e:

i. Belief in an organising Force in the Universe

It is the most important element to the concept of spirituality as it is related to the spiritual health and wellness.

ii. Connectedness

This connectedness can be a feeling or state of being one with others, one with nature or one with universe.

iii. Faith

It means that the individual believes and hopes that his/her worldview is a true depiction of reality.

iv. Movement towards Compassion

It is a behaviour in which the individual does not act selfishly. He will understand and act in a compassionate way to create a better world.

v. Ability to make meaning of life

This element allows an individual a sense that his life is truly worth living.

vi. Ability to make meaning of death

iv: Sweeney and Witmer Wheel of Wellness

The model considers wellness as a way of life geared to optimal health in which the mind, body and spirit are integrated, and an individual can live fully (Myers et al, 2000: Sweeney \& Witmer, 1991). The model integrates five life tasks, spirituality, self-direction, work and leisure, friendship and love with subtasks that are associated with the development of each life task. Spirituality is prominent in this model and is defined as "an awareness of a being or force that transcends the material aspects of life and give a deep sense of wholeness or connectedness to the universe (Myers et al, 2000, p. 253.)

\section{v. Islam Focusing Project of Afghanistan}

A good example of Islamic psychological treatment can be seen in Pat Omidian and Nina Joy Lawrence (2007). They introduced "Islam Focusing Project of Afghanistan", in which they have been involved for over 5 years. They take the approach of empowerment and community/family sharing based on public health model that uses preventive model and primary health care methods, rather than clinical or tertiary care modalities.

The approaches taken are public health, community level efforts that reflect a preventive, broad based methodology for dealing with trauma in a non-clinical way. This focusing model mirrors many of the actions of Sufism, the branch of esoteric and mystical Islam practiced at the periphery of Islamic tradition. This model is based on two main tenets of Sufism. The first is that, according to the Quran God is closer to each person than each is to his or her own jugular vein.

"It was We who created man, and We know, what suggestions his soul makes to him: for We are nearer to him than (his) jugular vein (Quran, $50: 16$ )

It means that one does not need to look far for support from God when one is in trouble or feeling emotional pain. This leads to the second concept of Sufi tradition that God is found in each of us. (Pat Omidian and Nina Joy Lawrence, 2007)

vii. Total Disaster Risk management (TDRM) 
TDRM is an approach adopted since 2005 by MERCY Malaysia, an international organization involved in the delivery of medical and humanitarian aid to vulnerable communities both at local and international level. This TDRM applies disaster risk management to all the phases of the disaster management cycle i.e., emergency response, recovery, prevention/mitigation and preparedness/ readiness.

The first phase, i.e the emergency response aims to ensure that effective responses such as rescue efforts and emergency medical assistance are in place when a disaster has taken place. For the second phase, i.e., recovery, it involves among others rehabilitation, disaster-resilient reconstruction efforts and livelihood support.

The third phase is about prevention or mitigation. It focuses on efforts to prevent or mitigate damage when a disaster strikes such as the construction and operation of meteorological observation systems to help prevent and mitigate damage in the event of an earthquake, flood, landslide or storm. The final phase called preparedness or readiness. This phase is crucial as it places the importance of hazard maps, food, as well as emergency kits and all vital factors that helps to minimise the impacts of a disaster. Even though TDRM covers all important stages relating to disaster, the details about the psych- spiritual support that include the framework, elements, way or methods are not available.

From the above discussion on the existing models, it can be argued that the there is no such comprehensive psycho spiritual support system as they provide only the general stages of action to be done for spiritually supporting the disaster victims. It does not cover the ways or modules that should be practiced by the victims to recover from their emotional and mental sufferings. Many existing models of holistic wellness include spirituality as a component however, there is no model that identify spiritual wellness as the primary focus that influences all aspects of an individual's life.

\section{Conclusion}

In conclusion, providing professional psycho-spiritual support are crucial element to mitigate any long-term adverse psychological impact following a disaster. From the exploratory studies, researchers believe in the important connection of religion and spirituality with health and wellness of an individual life. They are significant in achieving sense of personal control in a situation that evokes feelings of distress and helplessness. For the theory of change, faith is a powerful change agent. Those for people of faith, such principles are often considered above all other influences. Unfortunately, despites the importance of religion, this exploratory study on the existing psycho-spiritual support systems finds there is an absence of support system which comprehensively adopts specific criteria and methods of psycho-spiritual support from the religious point of view for disaster victims. This research also finds numerous models of psycho-spiritual support provided by both local and international organizations in all over the world. However, there is no comprehensive and standard model adopted. Thus, this research suggests that a comprehensive religious-based psycho-spiritual support system should be formulated to provide an alternative healing method for disaster victims.

\section{Acknowledgment}

This work was supported in part by Malaysian Ministry of Education and Universiti Teknologi MARA (UiTM) under Grant No. (REF: 600-IRMI/FRGS 5/3 (001/2017).

\section{References}

Aisha Hamdan, (2008). Cognitive Restructuring: An Islamic Perspective, Journal of Muslim Mental Health, 3:99-116.

Alexander Moreira-Almeida, Harold G. Koenig. (2006). Retaining the meaning of the words religiousness and spirituality: A commentary on the WHOQOL SRPB group's "A cross-cultural study of spirituality, religion, and personal beliefs as components of quality of life, Social Science \& Medicine, 63 (4), 843-845.

Bonanno, G. A. (2004). Loss, Trauma, and Human Resillience: Have We Underestimated the Human Capacity to Thrive After Extremely Aversive Events? American Psychologist, Vol. 59 (1), 20-28 .

Che Haslina Abdullah et. al (2012). Generalized Anxiety Disorder (GAD) from Islamic and Western Perspectives. World Journal of Islamic History and Civilization, 2 (1): 44-52, doi.org/ 10.1007/978-1-4939-7148-0_1

Conference, W. H. O., Aspects, H., \& Disaster, T. (2018). Humanitarian Health Action Purpose 
statements for panels and sessions.

Hung-Ru Lin \& Susan M. Bauer-Wu (2003). Psycho-spiritual well-being in patients with advanced cancer: an integrative review of the literature Religion, Spirituality and Health: Research and Clinical Application. Integrative Literature Reviews And Meta-Analyses. Blackwell Publishing Ltd

IFRC. (2016). World Disasters Report. International Federation of Red Cross and Red Crescent Societies (Vol. 91). https://doi.org/10.2307/2998097

Iqra Sense, (2013). Healing and Shifa from Quran and Sunnah: Spiritual Cures for Physical and Spiritual Conditions based on Islamic Guidelines Paperback - June 7.

Kucera. (2017). The Potential of Spirituality for the Treatment of Organizational Trauma, in The Impact of Organizational Trauma on Workplace, Czech Republic, University of Economics, 23. DOI: 10.4018/978-1-5225-2021-4.ch013.

Melanie, P. \& Peggy, .(2005), Holistic Flow Model, of Spiritual Wellness, Counseling and Values, 49, 106.

Michael Galea (2008). The Impact of Child Abuse on the Psycho-Spiritual and Religious Status of Maltese College Students. Pastoral Psychology (2008) 57,147-159

Moore, L.V. (2014). Working in Conflict: A Faith Based Toolkit for Islamic Relief. Retrieved from www.islamic-relief.org

Nasir, R., Zainah, A. Z., \& Khairudin, R. (2012). Psychological effects on victims of the Johor Flood 2006/2007. Asian Social Science, 8(8), 126-133. https://doi.org/10.5539/ass.v8n8p126

Nooria Mehraby. (2003). Islamic beliefs when dealing with loss, Psychotherapy in Australia, Vol. 9 , Issue No. 2

O'Connel, E., Abbot, RP, White RS. (2017) Emotions and Belief after a Disaster: A Comparative Analysis of Haiti and Indonesia, Disaster, 41(4), 803-827. doi: 10.1111/disa.12227.

Pamela V. V., \& Thomas, E. S., (2002), Finding Something to Do: The Disaster Continuity Care Model, Brief Treatment and Crisis Intervention 183-196.

Pat Omidian and Nina Joy Lawrence. (2007). A Community Based Approach To Focusing: The Islam and Focusing Project of Afghanistan. The Folio. 152.

Pargament, K. I. (1997) The psychology of Religion and Coping: Theory Research, Practice, New York: Guilford.

Pransky \& Kelley, (2014), Kelley, T. M. (2014). Three Principles for Realizing Mental Health: A New Psychospiritual View. Journal of Creativity in Mental Health, 9(1), 53-68. https://doi.org/ 10.1080/15401383.2013.875864

Qamrul Khanson. (2011). Psychological healing, an Islamic Thought of Intelectual Fitness,

R. Nasir, A.Z. Zainah \& R. Khairudin, (2012). Psycholoical Effectss on Victims of the Johor Flood 2006/2007, Asian Social Science, 8(8), 126-133, doi: 10.5539/ass.v8n8p126.

Santiago P.N., Oravec G.J., Ursano R.J. (2018) War, Sleep and PTSD War, and War-Related Trauma: An Overview. In: Vermetten E., Germain A., Neylan T. (eds) Sleep and CombatRelated Post Traumatic Stress Disorder. Springer, New York, NY

Schuster, M. A., Stein, B. D., Jaycox, L. H., et al (2001) A national survey of stress reactions after the September 11, 2001, terrorist attacks. New England Journal of Medicine, 345, 1507-1512.

Shadiya Mohamed S. Baqutayan.( 2011). An Innovative Islamic Counseling. International Journal of Humanities and Social Science. Vol. 1 No. 21 [Special Issue - December 2011]. 178

Shaista (2012). Addressing depression in Muslim communities. Bradford: University of Leeds.

Sipon, Nasrah, Nazli, Abdullah, \& Othman, (2014) Stress and Religious Coping Among Flood Victims, Procedia - Social and Behavioral Sciences, 140 (july), 605-608. :/foi.org/ 10.1080/15401383.2013.875864.

Suhaimi, A. W. \& Marzuki, N. A. (2016). The Importance of Psychological Preparedness among Flood Victims, The European Proceedings of Social \& Behavioural Sciences, 157-162).

Suresh Sundram, et. al, (2008), Psychosocial responses to disaster: An Asian perspective. Asian Journal of Psychiatry 1. Elsevier publication, 7-14.

Waqi Suhaimi, A., Ahmad Marzuki, N., \& Author, C. (2016). The Importance of Psychological Preparedness among Flood Victims. The European Proceedings of Social \& Behavioural Sciences, 158-168. https://doi.org/10.15405/epsbs.2016.08.23

WHO. (2011). War Trauma Foundation and World Vision International, Psychological First Aid: Guide for field workers, WHO, Geneva. 